\title{
Experimental Investigation into Vibration Characteristics for Damage Minimization in a Lapping Process
}

\author{
J. Suwatthikul, ${ }^{1}$ S. Sornmuang, ${ }^{1}$ T. Yaemglin, ${ }^{2}$ I. Cheowanish, ${ }^{2}$ and C. Supavasuthi ${ }^{2}$ \\ ${ }^{1}$ Advanced Automation and Electronics Research Unit, National Electronics and Computer Technology Center, \\ Pathum Thani 12120, Thailand \\ ${ }^{2}$ Western Digital (Thailand) Co., Ltd., Ayutthaya 13160, Thailand \\ Correspondence should be addressed to J. Suwatthikul; jittiwut.suwatthikul@nectec.or.th
}

Received 21 December 2015; Revised 9 February 2016; Accepted 14 February 2016

Academic Editor: Arturo Garcia-Perez

Copyright ( $\odot 2016$ J. Suwatthikul et al. This is an open access article distributed under the Creative Commons Attribution License, which permits unrestricted use, distribution, and reproduction in any medium, provided the original work is properly cited.

\begin{abstract}
Lapping machines are used in a hard disk rough lapping process where a workpiece (a wafer row bar) is locked with a robot arm and rubbed on a lap plate. In this process, the lap plate's condition and lifetime are among important concerned factors. The lifetime can be too short due to the plate being accidentally scratched by the workpiece during lapping. This problem leads to undesired consequences such as machine downtime and excessive plate material usage. This paper presents an experimental investigation into vibration characteristics of passed and failed lapping scenarios and discusses a potential solution to minimize the serious damage so-called "plate scratch" which intermittently occurs in such process. The experimental results show that, by in situ monitoring vibration and utilizing artificial intelligence, damage minimization can be possible.
\end{abstract}

\section{Introduction}

Lapping or polishing is a process that produces a smooth and lustrous surface finish. This shiny smooth appearance results from the action of abrasive power and a polishing tool. It has been widely used in the production of optical lenses, metallic bearing surfaces, and products requiring excellent finishes [1-5]. In the silicon wafer and the hard disk drive (HDD) industry, removing materials from slider bars together with controlling the strip height $(\mathrm{SH})$ variation to the minimum value is the major purpose of the lapping process [6-12].

Figure 1 shows a schematic view of a lapping machine used in an HDD manufacturing process. It basically consists of a plate, a moving arm (or slider arm), a clamping tool (CT), and a place where a workpiece is fitted. The machine is controlled by proprietary software to operate in defined steps and some feedback signals, for instance, RPM and resistance, are used in the control loop. The process is finished when the resistance meets the specified value. Normally, wear from normal use does occur; therefore, plate replacement or refinishing is required.
A previous study reported that a plate replacement accounted for $16.2 \%$ of lapping machine downtime [13]. The replacement usually results from normal wear and, being focused on in this paper, the undesired damage so-called "plate scratch" (PS) as illustrated in Figure 2. So far, root causes of such damage have not yet been identified in any research or engineering studies since the damage occurs randomly and the available feedback signals are not a good indicator to pinpoint such causes. One of the suspected root causes is an improper wedge angle or a sudden angle change during lapping. Conventional damage prevention is the careful checks of machine configurations and the continuous manual observation by an operator during lapping. Nonetheless, once the damage becomes visible to the naked eye, the scratched surface has already been too serious and costly to be refinished.

The objective of this investigation is to find a solution to PS minimization by recognizing vibration patterns of the lapping machine during lapping. A hypothesis has been the fact that there should be aggressive abrasion between the workpiece and the plate when PS is beginning, thereby 


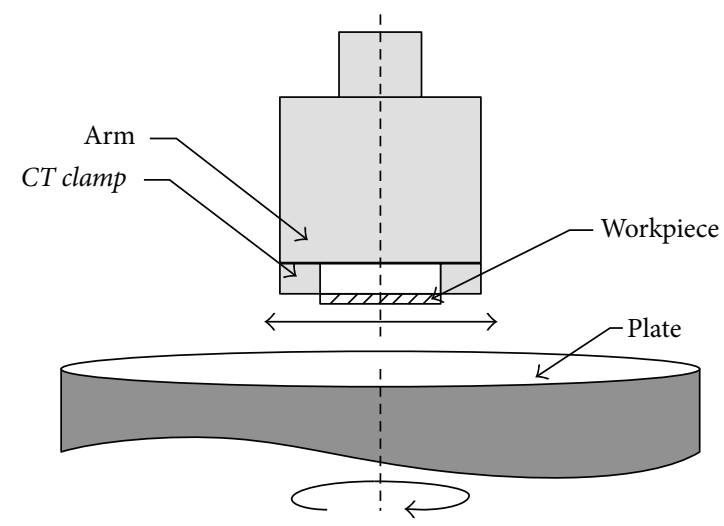

FIGURE 1: Schematic view of a lapping machine.

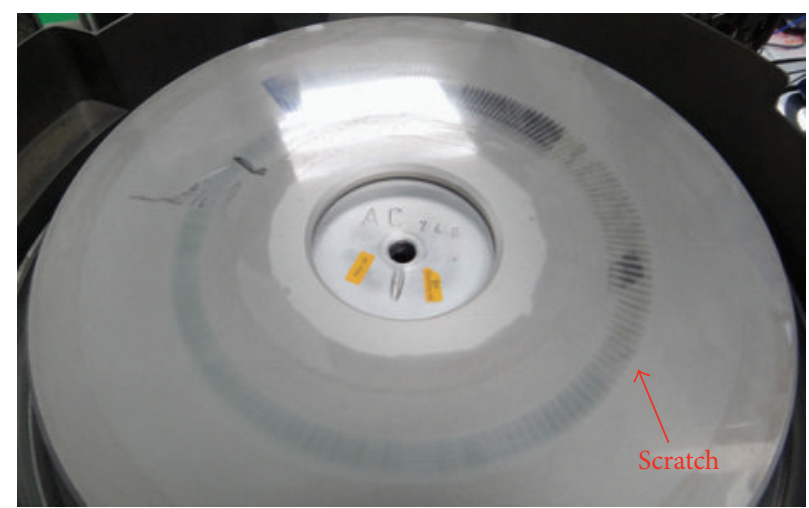

Figure 2: Plate scratch.

causing some abnormal vibration. If the vibration (if any) can be detected early enough, the machine would be stopped in time and the damage should be minimized.

The paper firstly presents an experimental investigation into vibration characteristics of passed and failed lapping scenarios (with and without damage). Then, a potential solution such as an AI-based detection system to minimize the damage is discussed. Kalman filter (KF) is used as a filter to eliminate the background noise of the signal. The signal spectra are generated and analyzed by using Fast Fourier Transform (FFT) technique. Finally, the conclusion of the paper is provided.

\section{Validation of the Vibration Sensor and Sensing Position}

Vibration is a repetitive, periodic, or oscillating response of a mechanical system [14]. Applications of vibration analysis have been found in many areas of engineering such as aeronautical and aerospace, civil, manufacturing, mechanical, and electrical applications [15-28]. In this work, in situ measurements of vibration using piezoelectric accelerometers are conducted to obtain vibration signals at the nearest position where the plate touches and rubs the workpiece. This section discusses basic understanding and validation of sensing positions on the machine and signals from the sensors.
2.1. Movement of the Vibration Sensor. A vibration sensor is originally designed by a manufacturer to be mounted firmly to a target and the DC bias voltage is set very close to zero. However, if the sensor is moved during operation for any reason, the bias level will change in relation to the direction and the magnitude of the movement. This section provides test results of the relationship between the sensor movement and the bias levels and directions. This behavior is found in "CT clamp in" and "CT clamp out" steps of the lapping process in the experiment section.

Sensor movements, as shown in Figure 3, are divided into two steps by moving the sensor in counterclockwise and clockwise directions between 0 and 360 degrees divided into four quarters and shifting every one quarter.

Test results of sensor movement are illustrated in Figure 4. It can be summarized that changes in the bias signal can indicate the sensor movement. The negative change occurs when the sensor moves either counterclockwise or clockwise between 0 and 180 degrees. However, the change is positive when moving sensor for both directions during 180-360 degrees.

2.2. Sensing Position. After considering the mechanical structure and the movement of the concerned machine, measurement points were defined and vibration sensors were attached to test the response as shown in Figure 5. The defined measurement positions are as follows: 


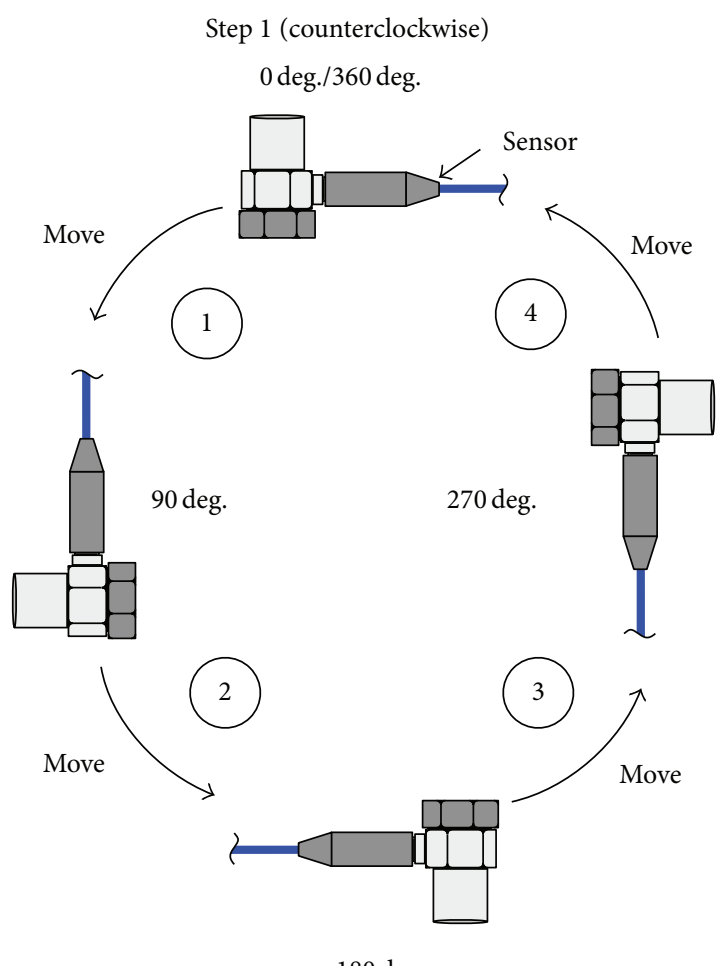

$180 \mathrm{deg}$.

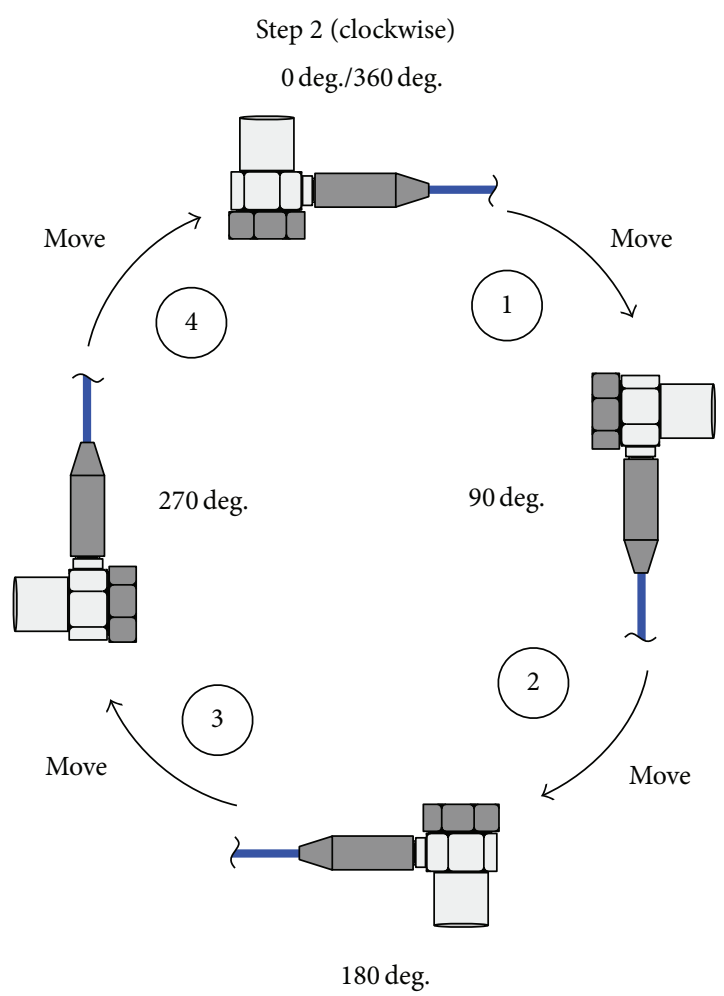

$180 \mathrm{deg}$.

Figure 3: Sensor movement tests.

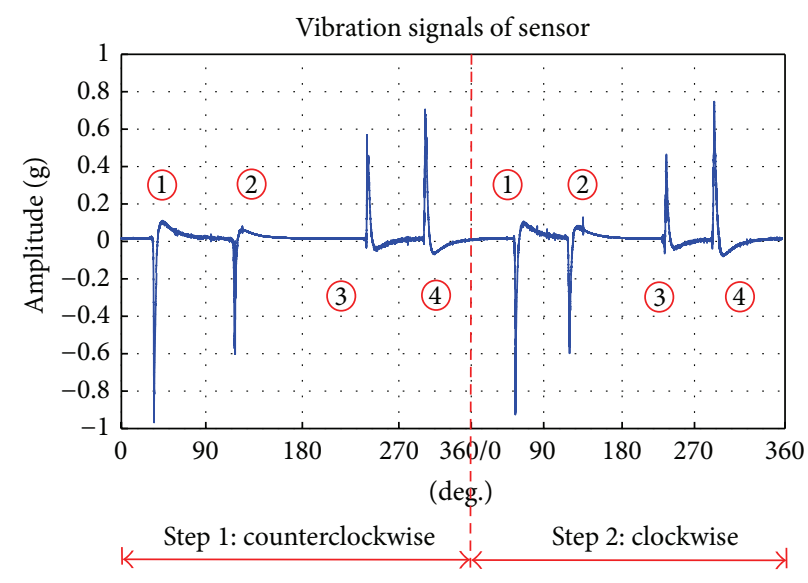

FIGURE 4: Signals from sensor movement tests.

(i) Row Tool (RT): the closest location to the original abrasion point between the plate and the workpiece.

(ii) Frame (Frame): at the arm which is a moving part of the machine.

(iii) Base (Base): the stationary part of the machine.

Step-by-step movement tests were then conducted to record and understand vibration signals. The machine was tested with the normal operating steps:

Step 1: Stationary, the machine is stationary.

Step 2: CT clamp in, the clamp moves to lock the workpiece to the arm.
Step 3: Landing, the arm moves and lands to touch the plate.

Step 4: Lapping, lapping starts and the plate rotates at the programmed speed.

Step 5: Lifting, the arm moves upwards and goes back.

Step 6: CT clamp out, the clamp is released to unload the workpiece.

The position test results are shown in Figures 6 and 7. For "Stationary" in Figure 6(a), no major vibration changes were detected. This can be regarded as background noise. Next, a sensor movement was detected in "CT clamp in" and "CT 


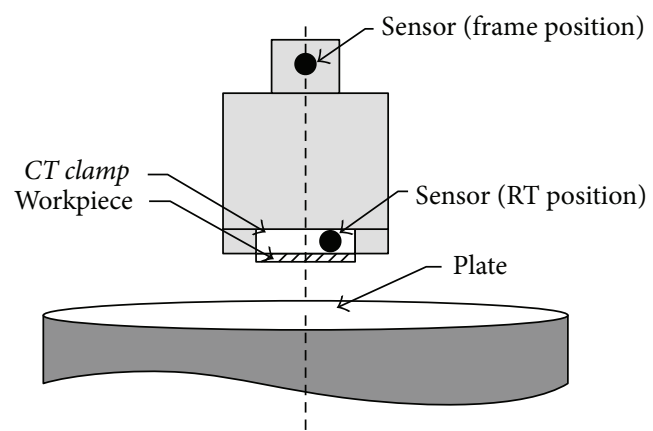

(a) Front view

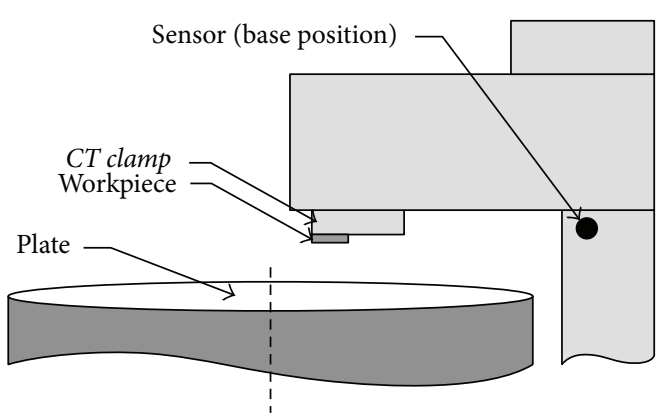

(b) Side view

FIGURE 5: Schematic view of sensor position tests.

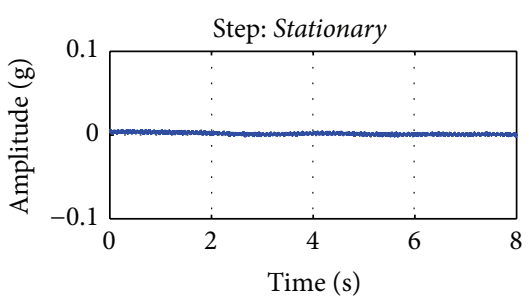

- Base

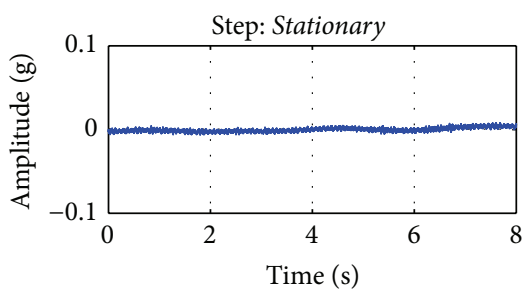

- Frame

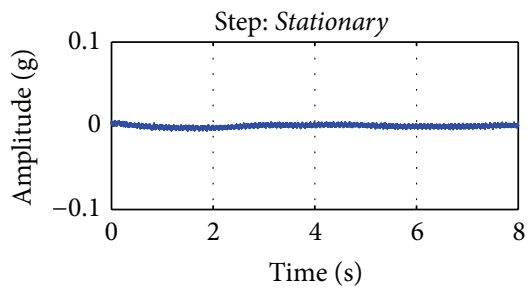

- RT

(a)

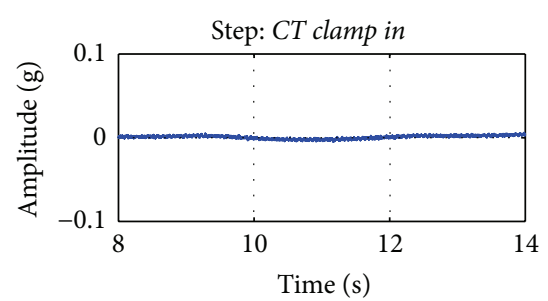

- Base

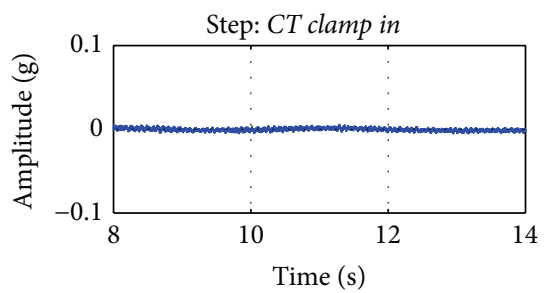

- Frame

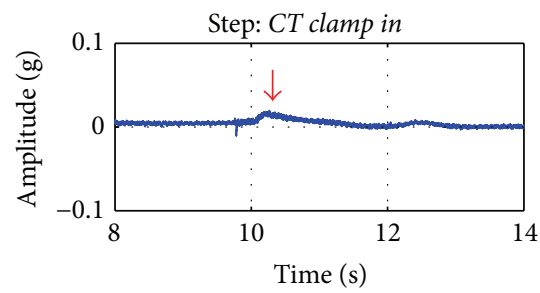

- RT

(b)
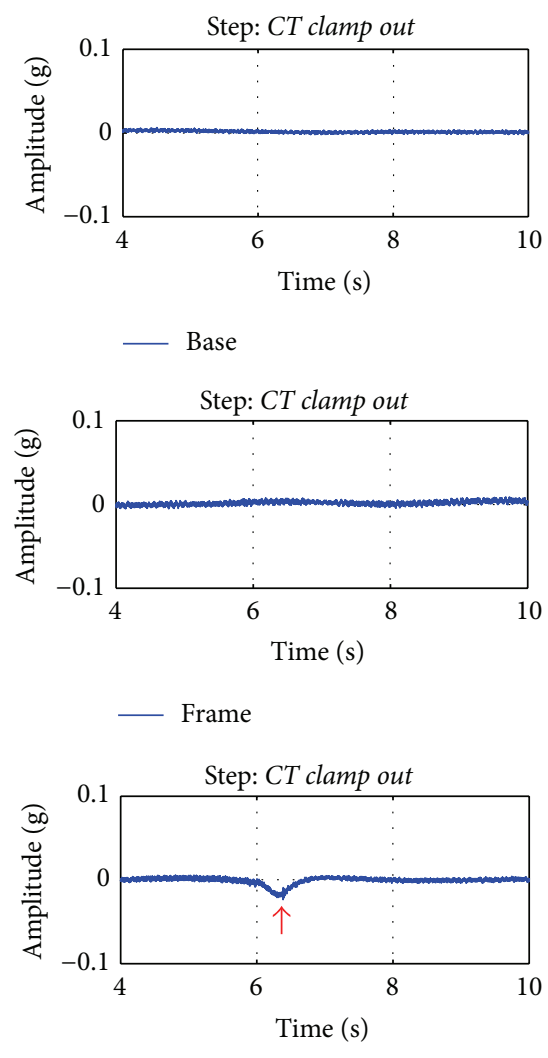

- RT

FIGURE 6: Vibration signals for "Stationary," "CT clamp in," and "CT clamp out" steps.

clamp out" steps at RT position as shown in Figures 6(b) and 6(c), respectively. In "CT clamp in" step, the positive change in the bias voltage can be measured when the clamp is moving to lock the workpiece, and this causes the sensor to move up slightly (as discussed in Section 2.1). Similarly, the negative signal occurs when the workpiece is moving down by the clamp release in "CT clamp out" step.

The vibration signals of "Landing" and "Lifting" steps can be measured at all sensing positions. For "Landing" step as shown in Figure $7(\mathrm{a})$, the arm moves to the position above the plate and then moves downward to touch it. In this step, vibration occurs and is damped down over time. Figure 7(b) shows the signals of the "Lifting" step; the behaviors are the same as "Landing" step but in reverse order.

According to the results, Base and Frame positions are sensitive to signals of the arm movement only. At RT position, in contrast, the sensor can sense all the test signals. Therefore, RT was finally selected to install the sensor for the experiment.

2.3. Kalman Filter (KF). The Kalman filter is a set of mathematical equations that provide an efficient computational 

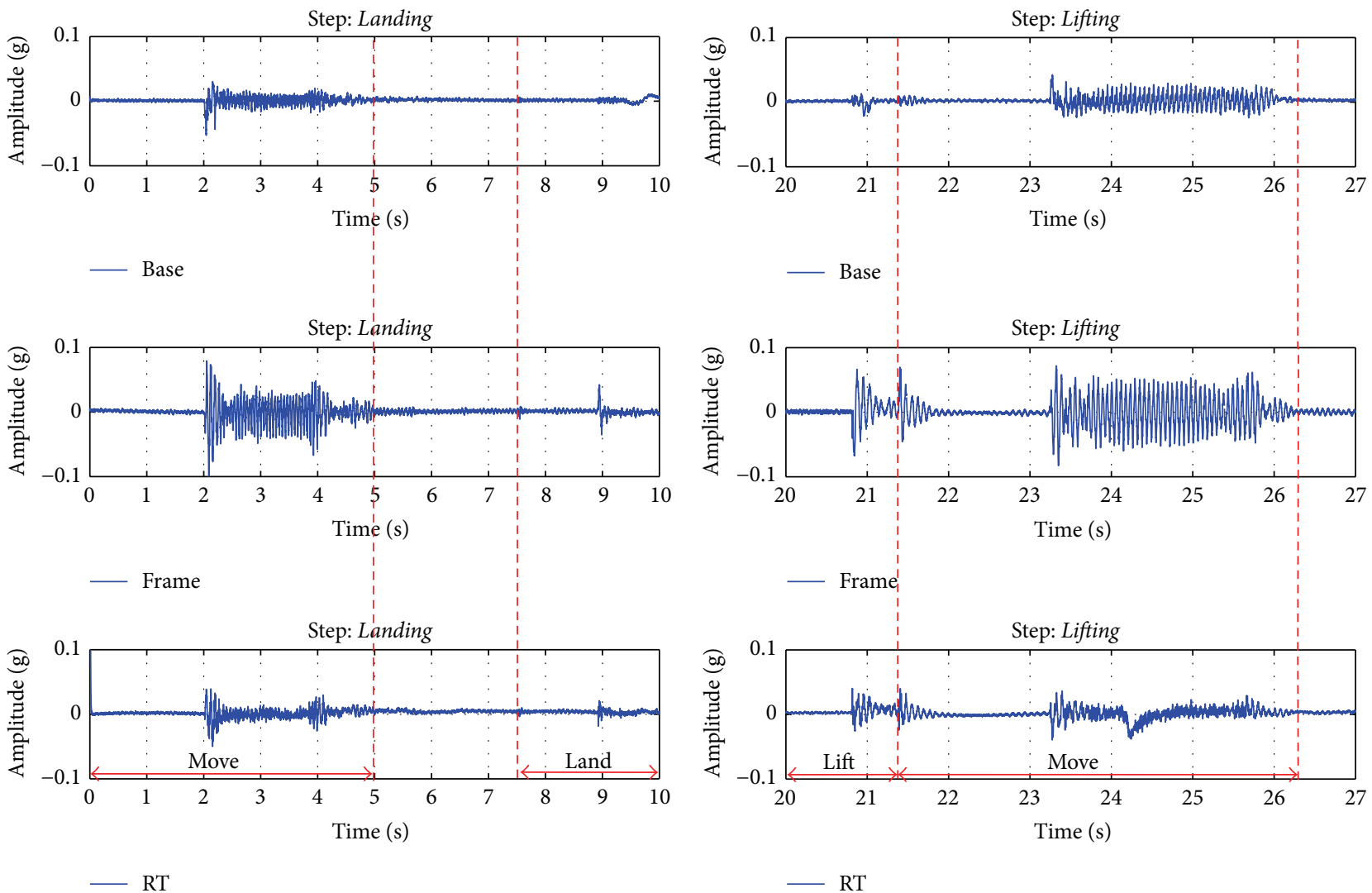

(a)

(b)

FIGURE 7: Vibration signals of "Landing” step.

means to estimate the state of a process, in a way that minimizes the mean of the squared error $[29,30]$. The filter is very powerful in several aspects: it supports estimations of past, present, and even future states, and it can do so even when the precise nature of the modeled system is unknown. The Kalman filter equations can be divided into two groups: time update equations and measurement update equations. The time update equations project forward the current state and error covariance estimates to obtain a priori estimates for the next step. The measurement update equations are responsible for incorporating a new measurement into a priori estimate to obtain an improved posterior estimate.

The time update equations can also be considered as predictor equations, while the measurement update equations can be considered as corrector equations. Mathematically, prediction of the state ahead $\left(\widehat{x}_{k}^{-}\right)$and the error covariance $\left(P_{k}^{-}\right)$may be represented as

$$
\begin{aligned}
& \widehat{x}_{k}^{-}=A \widehat{x}_{k-1}+B u_{k-1}, \\
& P_{k}^{-}=A P_{k-1} A^{T}+Q,
\end{aligned}
$$

where $Q$ is the process noise covariance. $A$ and $B$ are the form of linear stochastic difference equation.
The Kalman gain $\left(K_{k}\right)$, update estimate with measurement $\left(\widehat{x}_{k}\right)$, and update error covariance $\left(P_{k}\right)$ are defined in (2), (3), and (4), respectively. Consider

$$
\begin{aligned}
K_{k} & =P_{k}^{-} H^{T}\left(H P_{k}^{-} H^{T}+R\right)^{-1}, \\
\widehat{x}_{k} & =\widehat{x}_{k}^{-}+K_{k}\left(z_{k}-H \hat{x}_{k}^{-}\right), \\
P_{k} & =\left(1-K_{k} H\right) P_{k}^{-},
\end{aligned}
$$

where $R, z_{k}$, and $H$ are measurement noise covariance, the actual measurements of the process, and measurement Jacobian matrix at step $k$, respectively.

In this case, our noisy measurement is of the state directly; hence, $H=1$. The Kalman filter algorithm is described in the flowchart in Figure 8.

The flowchart summarizes the algorithm of Kalman filter which includes two main parts: the measurement part for computing the Kalman gain, updating the estimate of the measurement, and updating the error covariance and the time update part for prediction and estimation of state and error covariance.

A comparison of the collected vibration signal with and without using the filter is shown in Figure 9. The filtered signal (bottom) appears considerably smoother than the raw measured signal. 


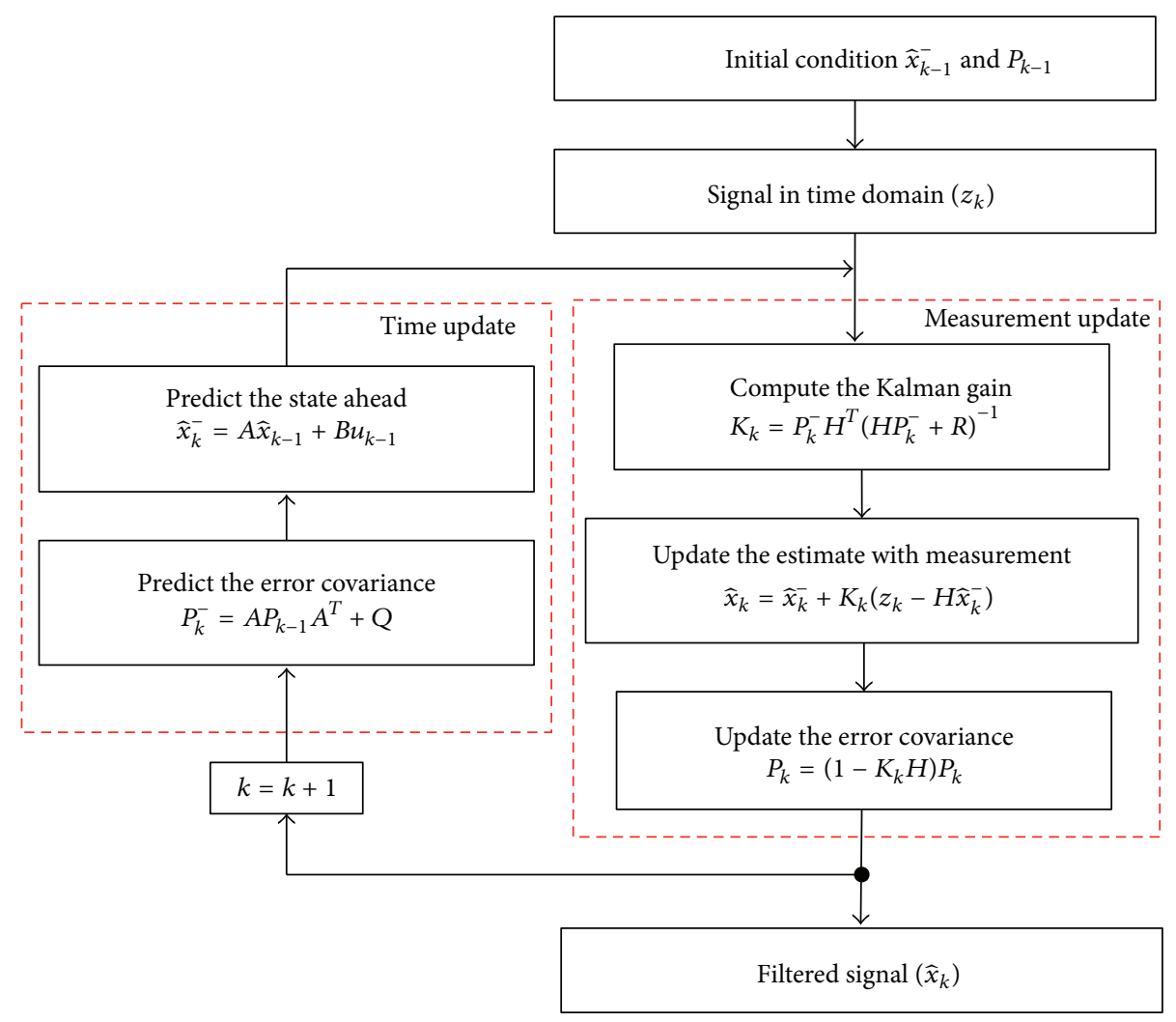

FIGURE 8: Flowchart of Kalman filter.

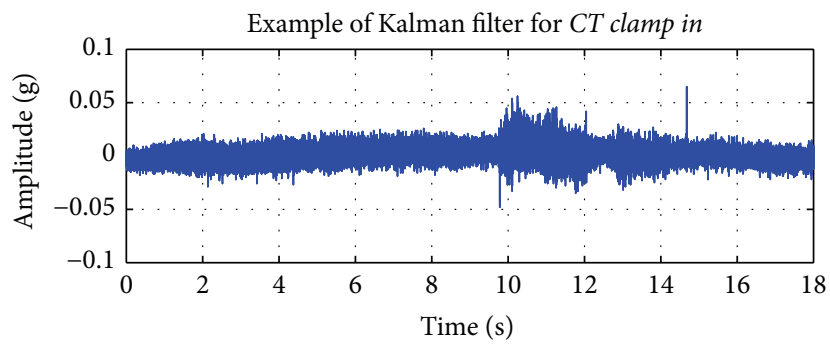

— Unfiltered signal

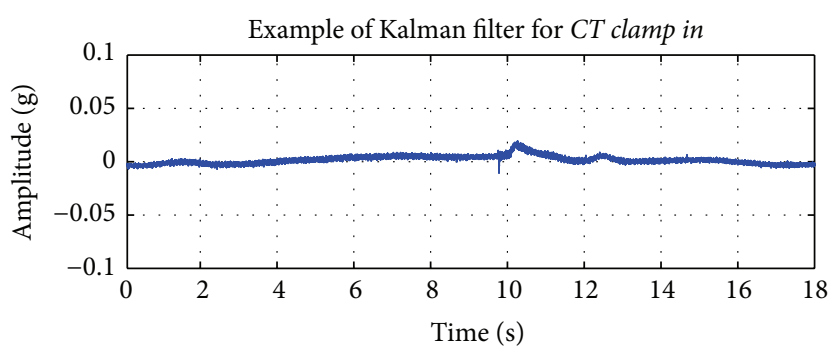

— Filtered signal

FIgURE 9: Example of filtered signal.

\section{Experimental Apparatus and Procedure}

Experiments with parameters listed in Table 1 to observe vibration and damage in rough lapping processes were conducted. The total workpieces were divided into two groups.
The first group was tested in a "healthy" (no damage) lapping process, and the other group was in an "unhealthy" (with damage) lapping process. In addition, the "unhealthy" process was tested under two conditions that have been suspected as the potential root causes of the damage: mechanical problem 


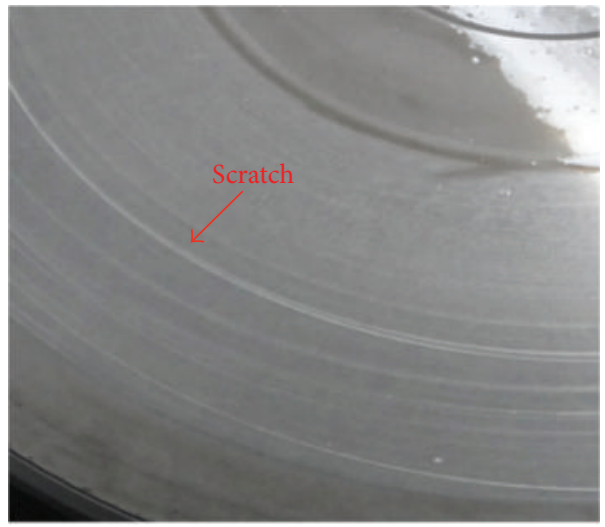

(a) Mechanical problem

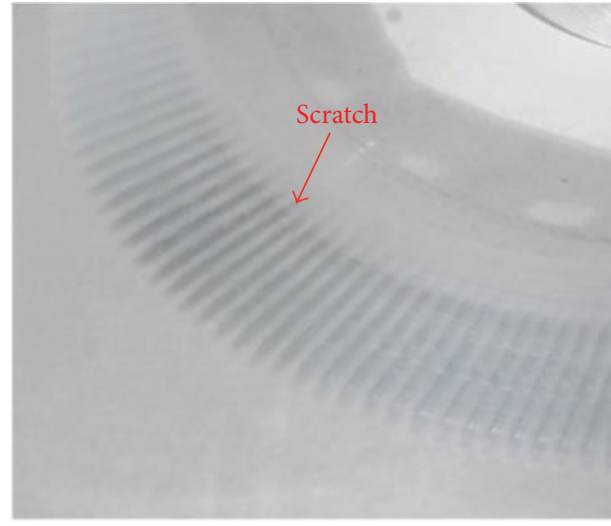

(b) Wedge angle problem

FIGURE 10: Scratches occurred in "unhealthy" lapping processes.

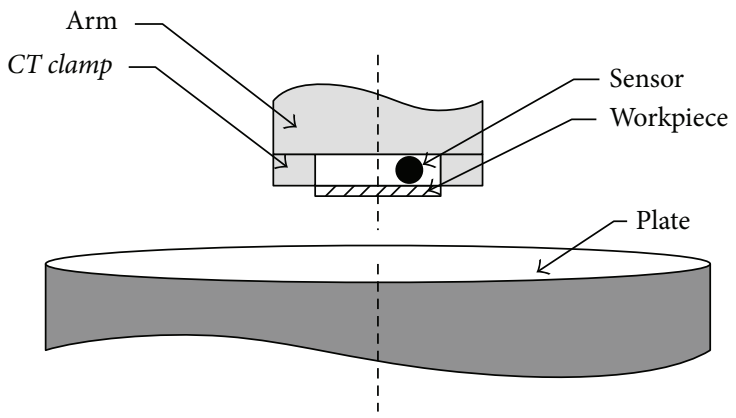

FIGURE 11: Schematic view of the experiment.

TABLE 1: Lapping parameters in the experiments.

\begin{tabular}{ll}
\hline Lapping parameters & Details \\
\hline Lapping control & $\begin{array}{l}\text { Constant lapping pressure, varying lap } \\
\text { plate speed for removal rate control }\end{array}$ \\
\hline Workpiece material & $\begin{array}{l}\text { Composite alumina oxide titanium } \\
\text { carbide (AlTiC) }\end{array}$ \\
\hline Diamond powder & Monocrystalline submicron diamond size \\
\hline
\end{tabular}

and wedge angle problem. These can result in scratches which are different in appearance as shown in Figure 10.

The mechanical problem was simulated by applying an impact at the back of the slider arm. This case is nonetheless interesting as the lapping process managed to continue and finish despite having the scratch. The wedge angle problem was simulated by swapping a workpiece that had been specifically assigned a wedge angle with another workpiece such that the angle became improper for lapping. In this case, if an operator cannot stop the machine in time, the problem will cause more severe damage to the plate than that of the mechanical problem.

The schematic view of the machine under the experiments is given in Figure 11. The sensor was firmly fitted at RT position which can best sense signals for all movements as previously discussed in Section 2. The rough lapping process was controlled by proprietary software to continuously operate the six major steps as presented above: Stationary, CT clamp in, Landing, Lapping, Lifting, and CT clamp out.

\section{Results and Discussion}

The test results include both "healthy" and "unhealthy" processes in which vibration signals were measured at RT position. The vibration characteristics of the "healthy" and "unhealthy" processes are summarized in Figures 12 and 13, respectively.

For the "healthy" process, the vibration in "Stationary" stepcan be considered as background noise as shown in Figure 12(a). In Figures 12(b) and 12(f), the vibration of "CT clamp in" and "CT clamp out" steps has opposite directions due to the sensor movement. The vibration signals of "Landing" and "Lifting" steps are illustrated in Figures 12(c) and 12(e), respectively. When the arm moves in, downward, upward, and out, the vibration can be clearly detected. Lastly and most importantly, smooth vibration signal of "Lapping" step in this "healthy" process was measured as depicted in Figure 12(d). The signal has similar amplitude level to that of the background noise in "Stationary" step but some high frequency components were detected. 


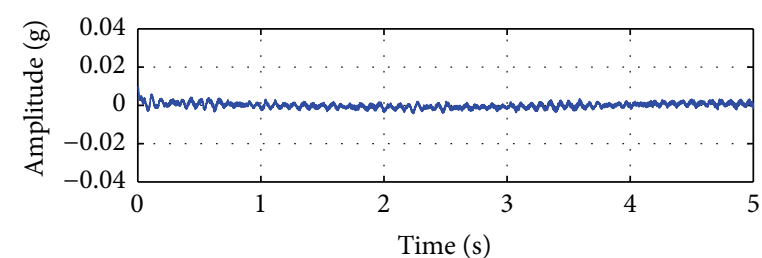

- Stationary

(a)

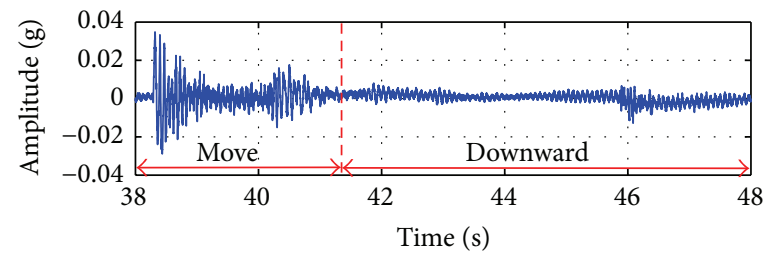

_ Landing

(c)

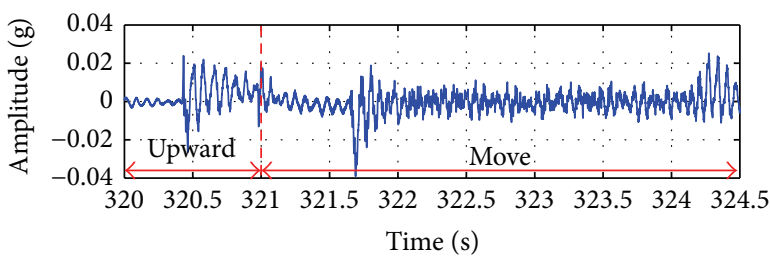

_ Lifting

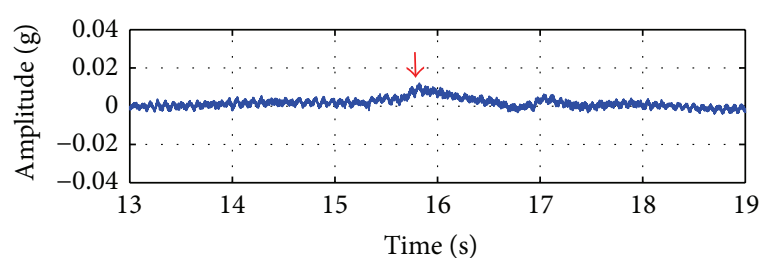

_ CT clamp in

(b)

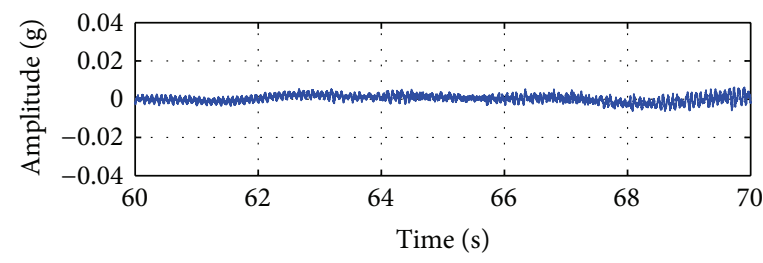

— Lapping

(d)

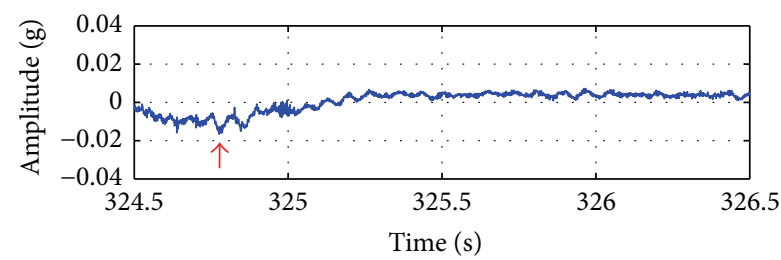

_ CT clamp out

(e)

(f)

FIGURE 12: Vibration of the "healthy" lapping process.

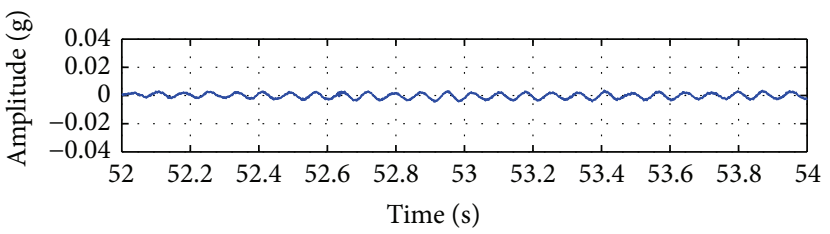

- Healthy

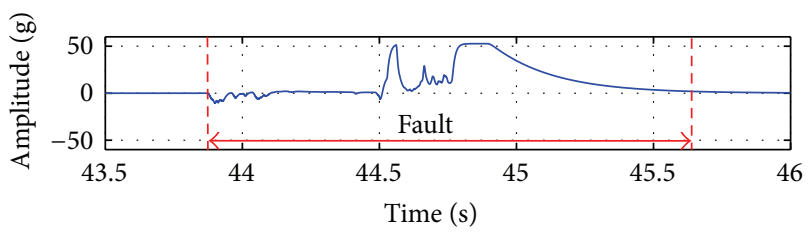

_ Unhealthy (mechanical)

(b)

(a)

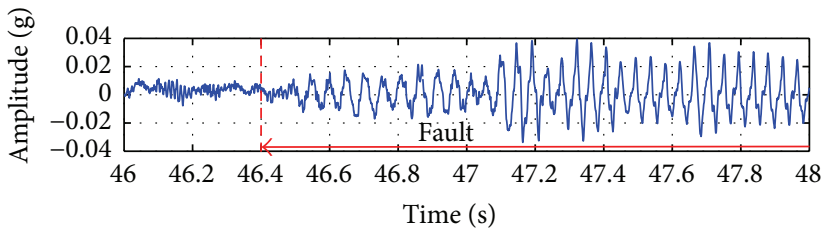

_ Unhealthy (wedge angle)

(c)

FIGURE 13: Vibration during lapping of the "healthy" and "unhealthy" processes.

For the "unhealthy" process, vibration characteristics in all steps except "Lapping" were similar to those of the "healthy" process. Figure 13 only compares the vibration signals in "Lapping" steps where scratches on the plates occurred during the "unhealthy" process. It can be clearly seen that the signals in "Lapping" of the "unhealthy" process are different from those of the "healthy" process. The test with the mechanical problem shows strong vibration as seen in Figure 13(b). According to an additional video record, PS was visible to the naked eye about 15 seconds afterward. This case is nonetheless interesting as the lapping process managed to continue and finish the process despite having 


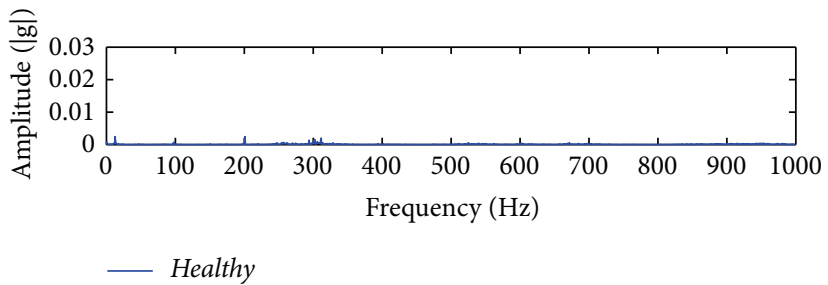

(a)

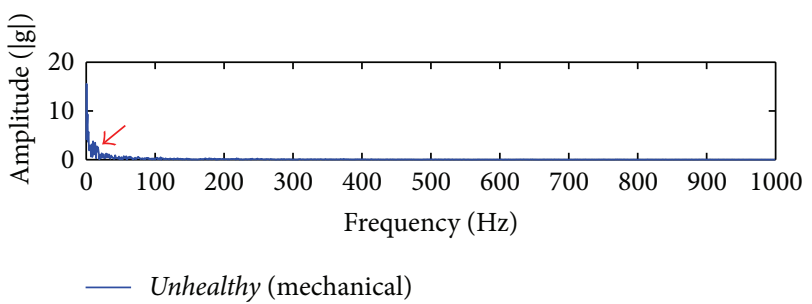

(b)

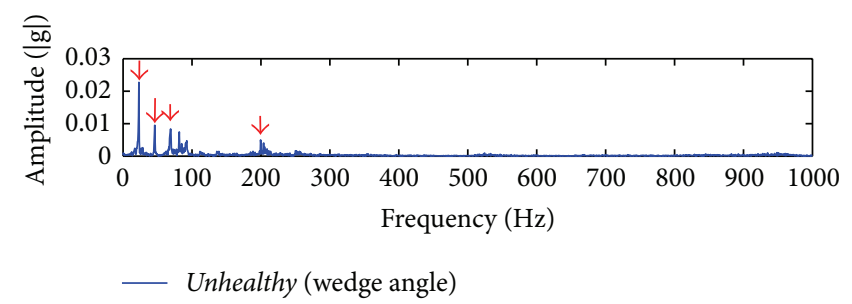

(c)

FIGURE 14: Vibration spectra of the "healthy" and "unhealthy" lapping processes.

PS. This may have been because the scratch was not repeated so that the machine was able to control lapping force to achieve the desired SH. Abnormal vibration of the test with the wedge angle problem can be measured at the beginning of the lapping and kept oscillating until the machine was stopped. The damage on the plate can be clearly discerned at 3 seconds later. In this case, the lapping failed to finish.

Frequency spectra of the vibration signals in "Lapping" steps are shown in Figure 14. The spectrum of the mechanical problem has higher peaks in low frequency than the "healthy" process and the wedge angle problem's spectra.

\section{Simulation of Scratch Detection by Using Neural-Expert Systems}

According to the experiments, the vibration signals are important components to identify whether a process is "healthy" or "unhealthy." The signals of the "unhealthy" process are different from the baseline characteristics in both time and frequency domains. Those signals can be classified by an artificial intelligence technique. This section demonstrates a simulation of scratch detection in the "Lapping" steps of the above experimental lapping processes by using a neural-expert system technique. Detection results show that it is possible to detect PS much earlier before it is visible to the naked eye; thus, the damage can be minimized.

5.1. Neural-Expert Systems. Expert systems and neural networks share common goals in attempting to imitate human intelligence and eventually create an intelligent machine [31]. However, they use very different means to achieve their goals. An expert system is used to diagnose and classify raw data before sending them to a neural network. This increases accuracy and reduces time in the neural process. The flowchart of the method for PS detection is summarized in Figure 15. The expert system part is designed to classify raw
TABLE 2: Subranges and thresholds for the neural-expert system.

\begin{tabular}{lccc}
\hline \multirow{2}{*}{ Range } & \multicolumn{2}{c}{ Vibration signals } & \multirow{2}{*}{ Threshold } \\
& Frequency $(\mathrm{Hz})$ & Time (s) & \\
\hline 1 & $0-25$ & - & 0.015 \\
2 & $25-100$ & - & 0.008 \\
3 & $150-200$ & - & 0.015 \\
4 & - & All (positive) & 0.03 \\
5 & - & $\mid$ All (negative) & 0.03 \\
\hline
\end{tabular}

data into a set of logic 0 or logic 1 by comparing input signals with specific thresholds. The logic set is then sent to the neural network which then calculates the output with parameters from training data and judges the output to be healthy or unhealthy by comparing with another threshold.

5.1.1. Expert System Part. As seen in Figures 13 and 14, the magnitudes of the "unhealthy" process are different from those of the "healthy" process. The different maximum values in each range $(|g|=$ amplitude $)$ and threshold levels were used by the neural-expert system to make a decision. The range of interest was classified as shown in Table 2.

Referring to Figure 15, the expert system part calculates maximum values of subranges which are represented by logic 0 or logic 1 from the threshold of each range. The output is defined as

$$
p=\left[\begin{array}{lllll}
p_{1} & p_{2} & p_{3} & p_{4} & p_{5}
\end{array}\right],
$$

where $p_{i}$ represents logic 0 or logic 1 which are used as inputs of the neural network part.

5.1.2. Neural Network Part. A neural network can be trained with historical data to perform a desired function by adjusting the weights $(w)$ and bias $(b)$ of the connections such that the outputs match the inputs. A set of neurons are combined 


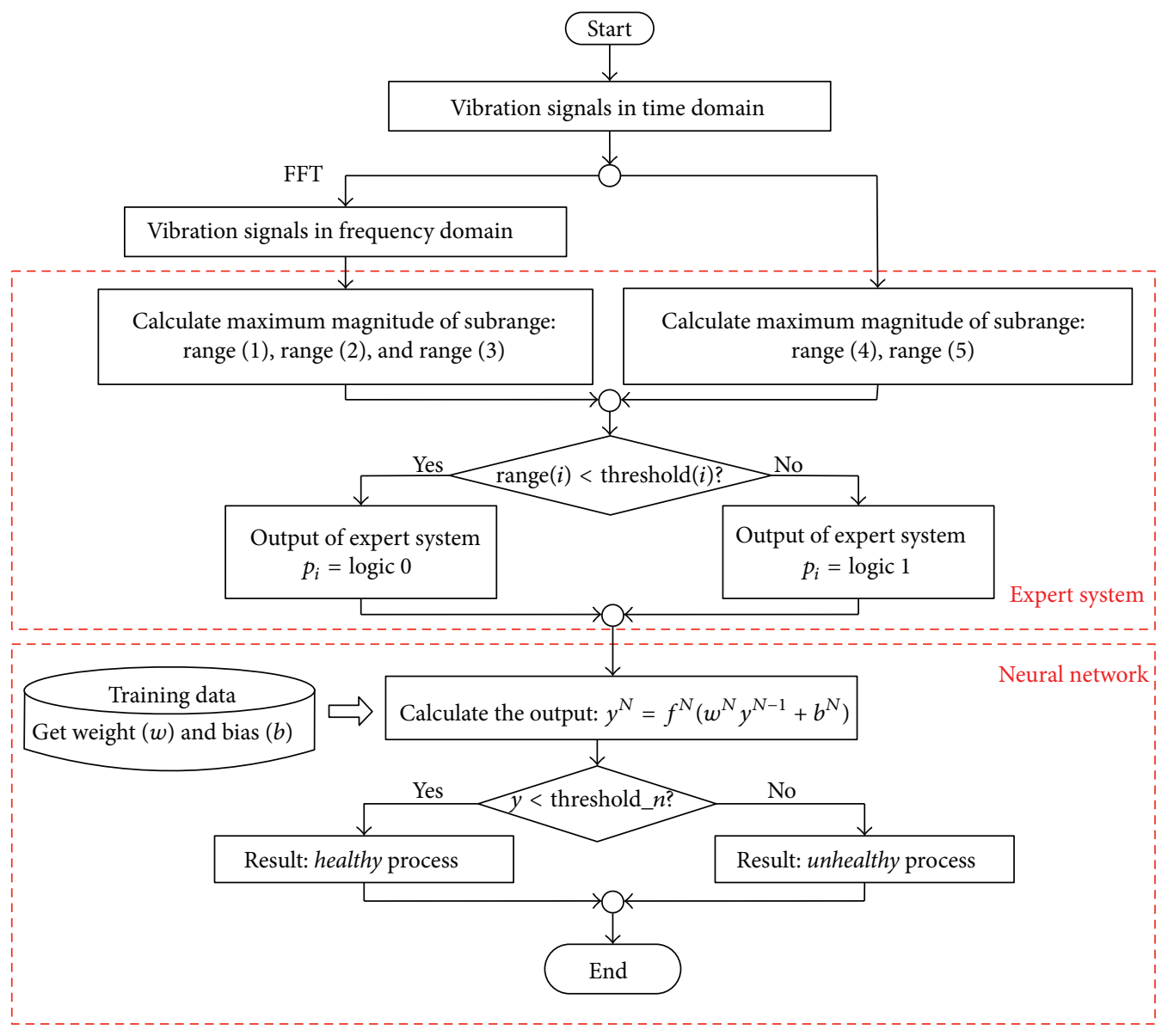

FIgURE 15: Flowchart of neural-expert systems.

in a layer and a network can consist of single or multiple layers, as shown in Figure 16. The general equations of ANNs are as follows:

$$
\begin{gathered}
y^{1}=f^{1}\left(w^{1} p+b^{1}\right) \\
y^{2}=f^{2}\left(w^{2} y^{1}+b^{2}\right) \\
\vdots \\
y^{N}=f^{N}\left(w^{N} y^{N-1}+b^{N}\right),
\end{gathered}
$$

$$
\begin{gathered}
b=\left[\begin{array}{c}
b_{1} \\
b_{2} \\
\vdots \\
b_{S}
\end{array}\right], \\
w=\left[\begin{array}{cccc}
w_{11} & w_{12} & \cdots & w_{1 R} \\
w_{21} & w_{22} & \cdots & w_{2 R} \\
\vdots & \vdots & & \vdots \\
w_{S 1} & w_{S 2} & \cdots & w_{S R}
\end{array}\right] .
\end{gathered}
$$

where

$$
p=\left[\begin{array}{c}
p_{1} \\
p_{2} \\
\vdots \\
p_{R}
\end{array}\right]
$$

The neural network model is trained with the experimental data by using Levenberg-Marquardt (LM) algorithm which is the fastest back-propagation algorithm and one of the efficient methods [32]. A feed-forward neural network is used and consists of an input layer (5 neurons), a 1-node output layer, and a hidden layer (35 neurons). The transfer functions are tansig, logsig, and logsig, respectively.

The detection system was implemented in a LabView and Matlab environment. An example of the user interface is depicted in Figure 17 where measured vibration signals, 


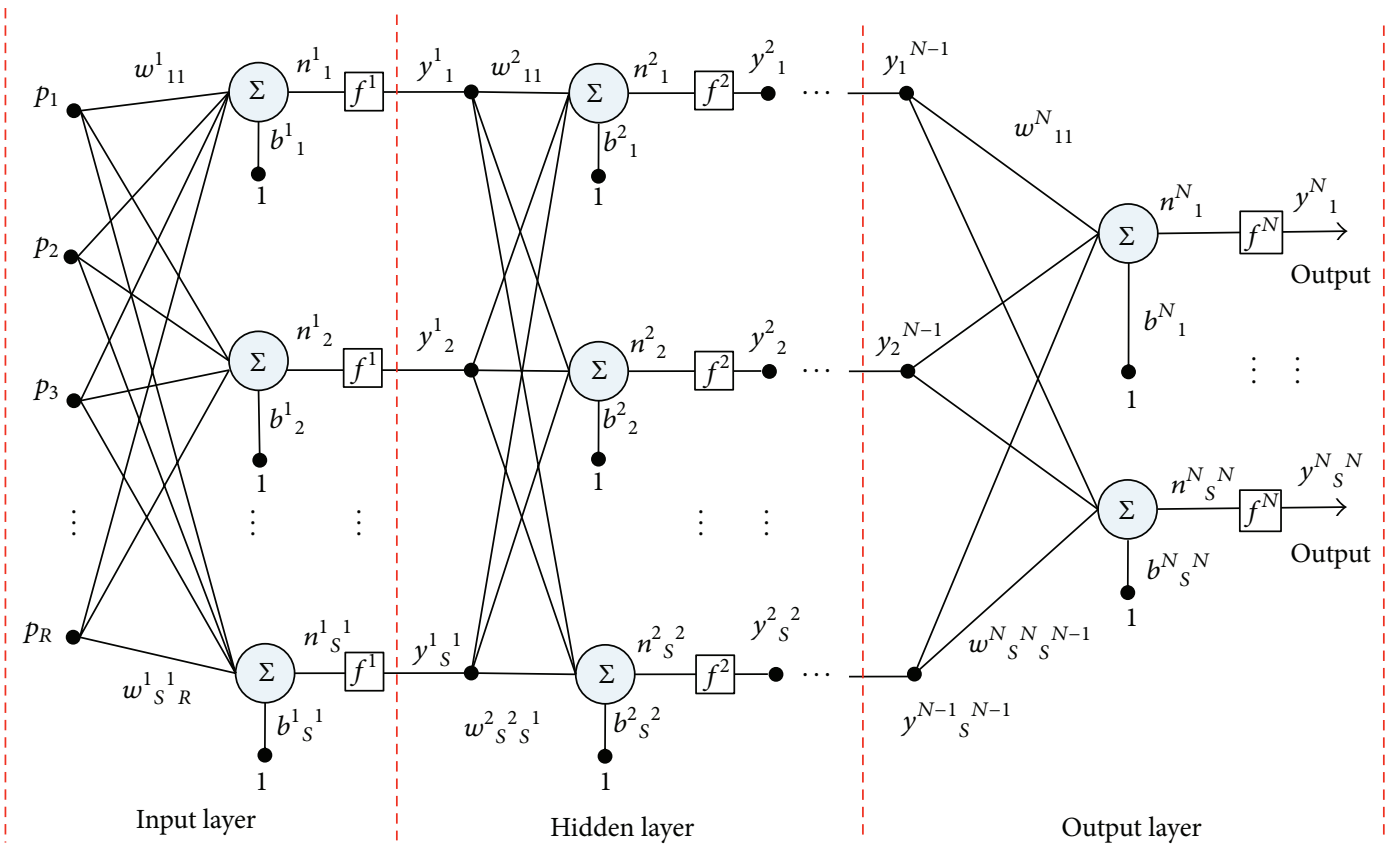

FIGURE 16: General structure of an artificial neural network.

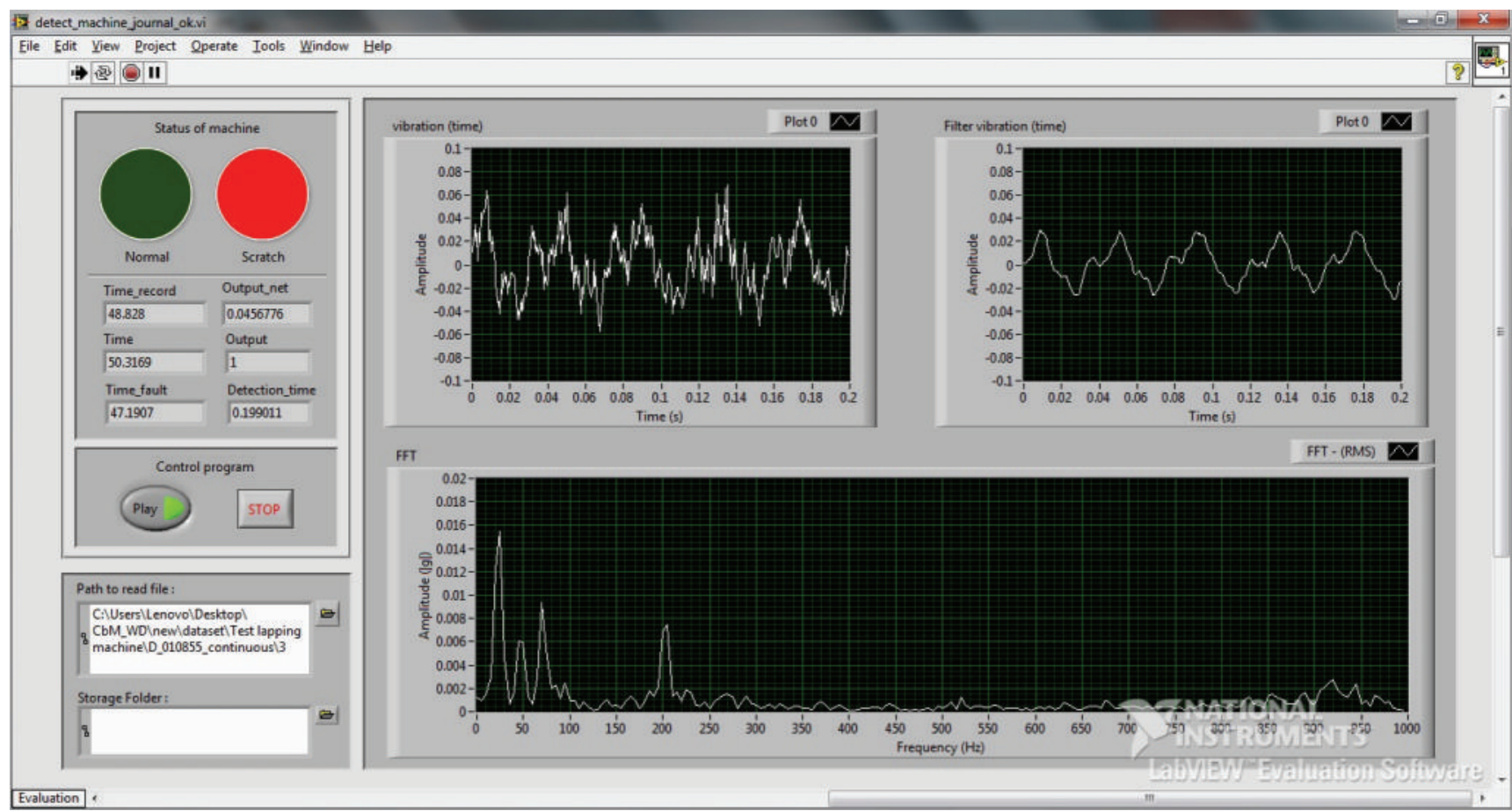

FIGURE 17: PS detection system.

fault messages, and detection times can be monitored and recorded.

5.2. Detection Results. Detection results are summarized in Tables 3 and 4 . Twenty-two datasets were tested. The accuracy of the detection system is $98 \%$ on average and the detection time is in the range of $0.2 \mathrm{~s}$. The $5 \%$ detection error came from the fact that the system was unable to classify the "healthy" input signals with high confidence so that they were declared as unknown. The system performed early detection before the two damage incidents were visible to the naked eye, which were recorded as 3 seconds for the mechanical problem and 15 seconds for the wedge angle problem (on average) as shown in Table 4 . The time recording started immediately after the 
TABLE 3: Detection results.

\begin{tabular}{lcc}
\hline Lapping process & Accuracy (\%) & $\begin{array}{c}\text { Detection time } \\
(\mathrm{s})\end{array}$ \\
\hline Healthy & 95 & - \\
Unhealthy (mechanical problem) & 100 & 0.21 \\
Unhealthy (wedge angle problem) & 100 & 0.20 \\
\hline Total & 98.33 & 0.205 \\
\hline
\end{tabular}

TABLE 4: Visible PS.

\begin{tabular}{lcc}
\hline Appearance & Type & $\begin{array}{c}\text { Averaged time } \\
\text { to be visible (s) }\end{array}$ \\
\hline & Mechanical & 3 \\
\hline & & \\
\hline
\end{tabular}

problem was applied. As such, it is possible that the process can be stopped by the detection system to prevent further serious damage.

\section{Conclusions}

This paper has presented an experimental investigation into vibration characteristics of a lapping machine in an HDD lapping process. The objective is to find a solution to PS minimization by recognizing vibration patterns of the lapping machine during lapping. The vibration signals in each normal operating step have their own patterns as presented and discussed above. Any anomalies that deviate from the baselines will potentially indicate undesired impacts or abrasion between the plate and the workpiece. In both "unhealthy" test cases conducted in this paper, abnormal vibration patterns are related to the original root causes and can be detected by the vibration sensor significantly earlier than being visible to an operator. It can be concluded in this investigation that there are detectable vibration signals at RT, generated by aggressive abrasion or impacts before PS occurs. Being able to detect and characterize the signals can enable us to stop lapping and to prevent further serious damage. Early detection of the anomalies can be achieved by a condition monitoring and fault detection system.

\section{Competing Interests}

The authors declare that there are no competing interests regarding the publication of this paper.

\section{Acknowledgments}

This work is sponsored by Western Digital (Thailand). The authors would like to thank the students from King Mongkut's University of Technology North Bangkok for their great support: Ms. Sumittra Viriyakitpattana and Ms. Kunjalin Sangrungruang.

\section{References}

[1] Y.-C. Chiou, R.-T. Lee, and C.-L. Yau, "A novel method of composite electroplating on lap in lapping process," International Journal of Machine Tools and Manufacture, vol. 47, no. 2, pp. 361367, 2007.

[2] M. P. Groover, Fundamental of Modern Manufacturing, John Wiley \& Sons, New York, NY, USA, 2002.

[3] N. J. Brown, "Some speculations on the mechanisms of abrasive grinding and polishing," Precision Engineering, vol. 9, no. 3, pp. 129-138, 1987.

[4] T. K. Doy, "Colloidal silica polishing based on micromechanical removal action and its applications," Sensors and Materials, vol. 3, pp. 153-167, 1988.

[5] T. Kasai, K. Horio, and A. Kobayashi, "Improvement of conventional polishing conditions for obtaining super smooth surfaces of glass and metal works," CIRP Annals-Manufacturing Technology, vol. 39, no. 1, pp. 321-324, 1990.

[6] Z. J. Pei, G. R. Fisher, and J. Liu, "Grinding of silicon wafers: a review from historical perspectives," International Journal of Machine Tools and Manufacture, vol. 48, no. 12-13, pp. 1297-1307, 2008.

[7] X. Zhu, C. Chung, C. S. Korach, and I. Kao, "Experimental study and modeling of the effect of mixed size abrasive grits on surface topology and removal rate in wafer lapping," Wear, vol. 305, no. 1-2, pp. 14-22, 2013.

[8] Y. Mei and K. A. Stelson, "Lapping control of hard disk drive heads," Journal of Dynamic Systems, Measurement and Control, vol. 123, no. 3, pp. 439-448, 2001.

[9] H. H. Gatzen, J. Christoph Maetzig, and M. K. Schwabe, "Precision machining of rigid disk head sliders," IEEE Transactions on Magnetics, vol. 32, no. 3, pp. 1843-1849, 1996.

[10] M. Jiang, S. Hao, and R. Komanduri, "On the advanced lapping process in the precision finishing of thin-film magnetic recording heads for rigid disc drives," Applied Physics A: Materials Science and Processing, vol. 77, no. 7, pp. 923-932, 2003.

[11] P. Wonglersak, P. Youngkong, and I. Cheowanish, "Classification of initial stripe height patterns using radial basis function neural network for proportional gain prediction," in Proceedings of the International Conference on Machine Learning and Data Analysis, Venice, Italy, April 2011.

[12] P. Wonglersak, P. Youngkong, and I. Cheowanish, "PD compensator for lapping process of hard disk drive heads," in Proceedings of the International Conference on Computer, Electrical, and Systems Sciences, and Engineering, Paris, France, December 2011.

[13] P. Maprachong and W. Tharmmapornphilas, "Increasing availability of lapping machine in a hard disk read/write head production process," in Proceedings of the IRES 4th International Conference, Kuala Lumpur, Malaysia, July 2015.

[14] W. Clarence, Vibration Fundamentals and Practice, CRC Press, 2000.

[15] S. Nandi, H. A. Toliyat, and X. Li, "Condition monitoring and fault diagnosis of electrical motors-a review," IEEE Transactions on Energy Conversion, vol. 20, no. 4, pp. 719-729, 2005. 
[16] F. P. Kopsaftopoulos and S. D. Fassois, "Vibration based health monitoring for a lightweight truss structure: experimental assessment of several statistical time series methods," International Journal of Machine Tool \& Manufacture, vol. 24, pp. 19771997, 2010.

[17] H. Wang, S. To, C. Y. Chan, C. F. Cheung, and W. B. Lee, "A theoretical and experimental investigation of the tool-tip vibration and its influence upon surface generation in singlepoint diamond turning," International Journal of Machine Tools and Manufacture, vol. 50, no. 3, pp. 241-252, 2010.

[18] F. Wu, T. Wang, and J. Lee, "An online adaptive condition-based maintenance method for mechanical systems," Mechanical Systems and Signal Processing, vol. 24, no. 8, pp. 2985-2995, 2010.

[19] P. K. Kankar, S. C. Sharma, and S. P. Harsha, "Fault diagnosis of ball bearings using continuous wavelet transform," Applied Soft Computing Journal, vol. 11, no. 2, pp. 2300-2312, 2011.

[20] S. Sornmuang and J. Suwatthikul, "Detection of a motor bearing shield fault using neural networks," in Proceedings of the 50th Annual Conference on Society of Instrument and Control Engineers (SICE '11), pp. 1260-1264, Tokyo, Japan, September 2011.

[21] J. Suwatthikul and S. Sornmuang, "Fault detection and diagnosis of a motor bearing shield," in Proceedings of the 6th IEEE International Conference on Intelligent Data Acquisition and Advanced Computing Systems (IDAACS '11), pp. 332-335, Prague, Czech Republic, September 2011.

[22] H. Su, K. T. Chong, and R. R. Kumar, "Vibration signal analysis for electrical fault detection of induction machine using neural networks," Neural Computing and Applications, vol. 20, no. 2, pp. 183-194, 2011.

[23] D. Zenunovic, M. Topalovic, and R. Folic, "Identification of modal parameters of bridges using ambient vibration measurements," Shock and Vibration, vol. 2015, Article ID 957841, 21 pages, 2015.

[24] J. Huang, Q. Su, T. Liu, and X. Wang, "Vibration and long-term performance analysis of pile-plank-supported low subgrade of ballastless track under excitation loads," Shock and Vibration, vol. 2015, Article ID 404627, 12 pages, 2015.

[25] A. Soleimani and S. E. Khadem, "Early fault detection of rotating machinery through chaotic vibration feature extraction of experimental data sets," Chaos, Solitons \& Fractals, vol. 78, pp. 61-75, 2015.

[26] D. Bayram and S. Şeker, "Anfis model for vibration signals based on aging process in electric motors," Soft Computing, vol. 19, no. 4, pp. 1107-1114, 2015.

[27] T. Natsuki, N. Matsuyama, and Q. Ni, "Vibration analysis of carbon nanotube-based resonator using nonlocal elasticity theory," Applied Physics A, vol. 120, no. 4, pp. 1309-1313, 2015.

[28] C. Ruiz-Cárcel, V. H. Jaramillo, D. Mba, J. R. Ottewill, and Y. Cao, "Combination of process and vibration data for improved condition monitoring of industrial systems working under variable operating conditions," Mechanical Systems and Signal Processing, vol. 66-67, pp. 699-714, 2016.

[29] R. E. Kalman, "A new approach to linear filtering and prediction problems," Journal of Basic Engineering, vol. 82, no. 1, pp. 35-45, 1960.

[30] G. Welch and G. Bishop, An Introduction to the Kalman Filter, UNC-Chapel Hill, 2006.

[31] M. Negnevititsky, Artificial Intelligence, Addison Wesley, 2001.

[32] H. Yu and B. M. Wilamowski, "Levenberg-marquardt training," in Industrial Electronics Handbook, CRC Press, 2011. 


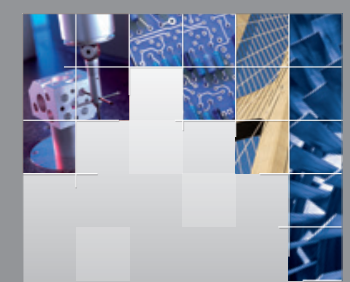

\section{Enfincering}
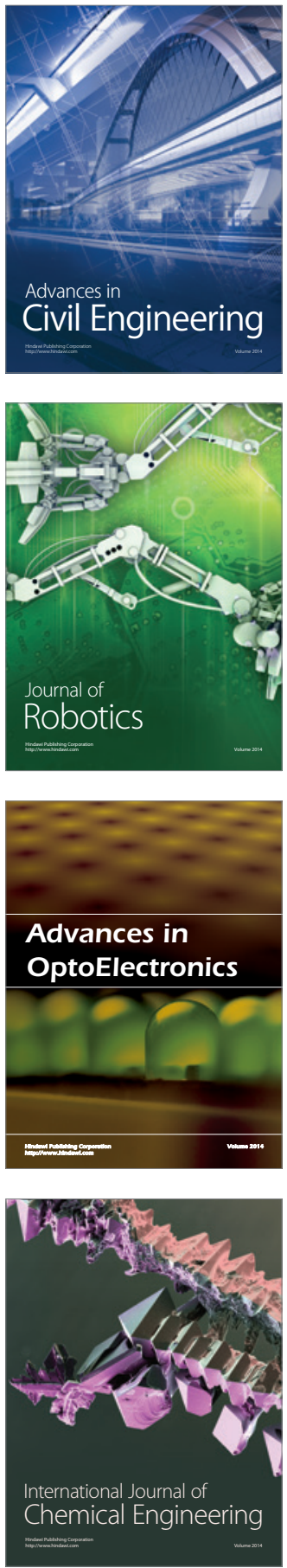

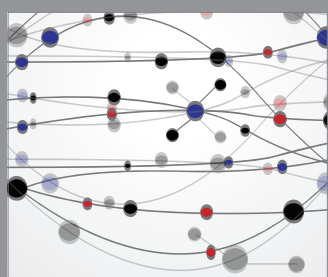

The Scientific World Journal

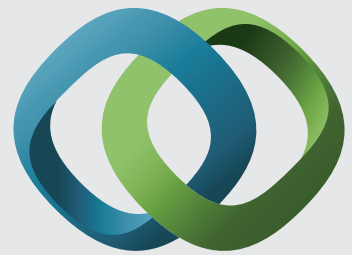

\section{Hindawi}

Submit your manuscripts at

http://www.hindawi.com
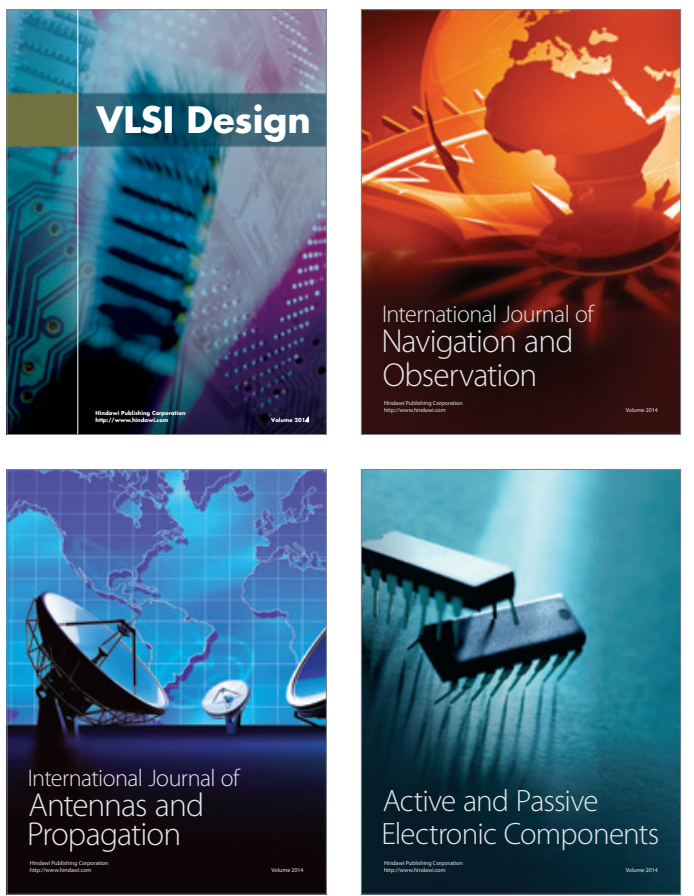
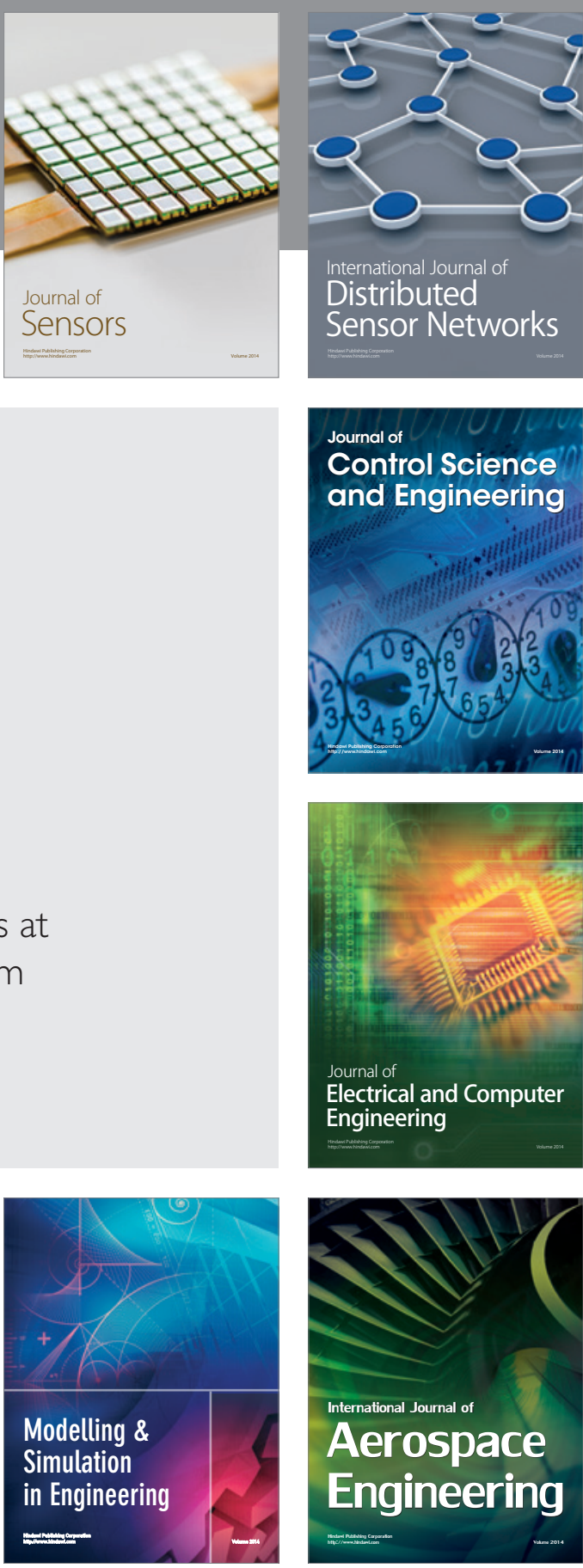

International Journal of

Distributed

Sensor Networks

Journal of

Control Science

and Engineering
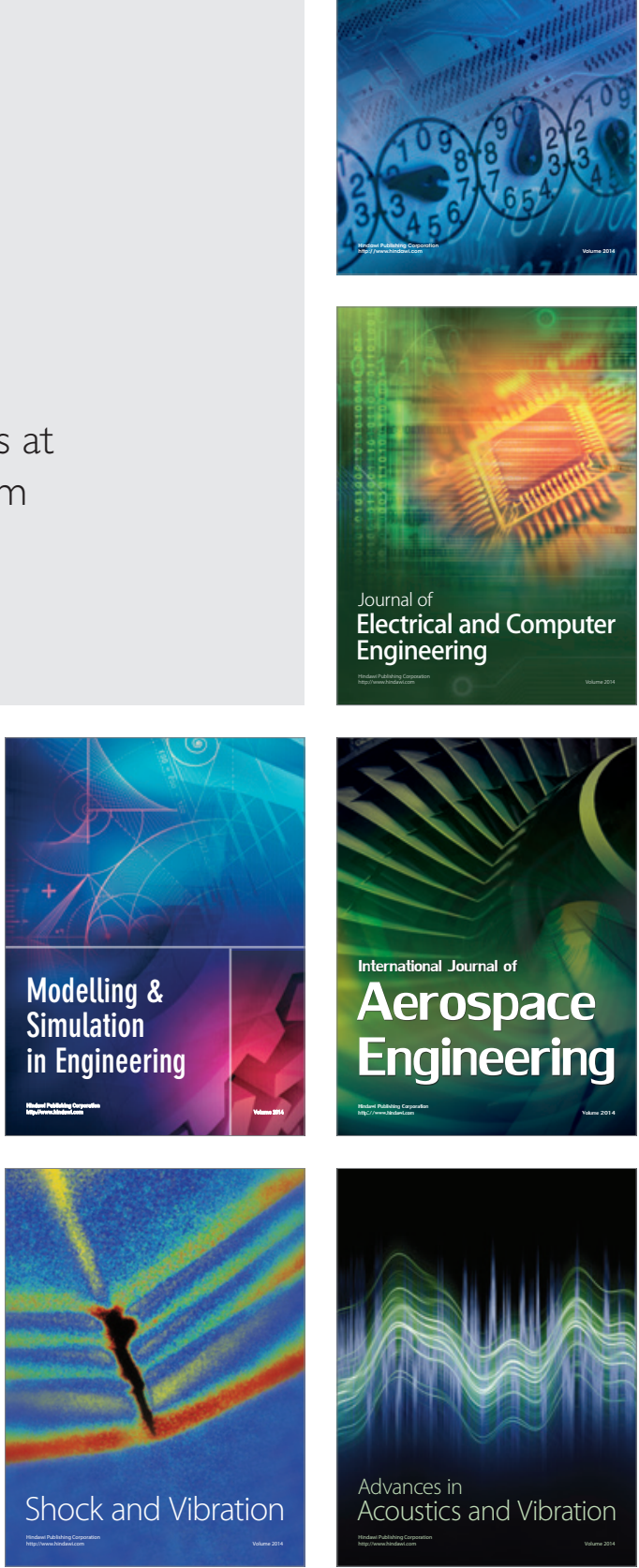